Boston University School of Law Scholarly Commons at Boston University School of Law

Faculty Scholarship

$8-2018$

\title{
Crime, Punishment, and Legal Error: A Review of the Experimental Literature
}

Kathryn Zeiler

Boston University School of Law

Erica Puccetti

Follow this and additional works at: https://scholarship.law.bu.edu/faculty_scholarship

Part of the Criminal Law Commons, Criminal Procedure Commons, and the Law Enforcement and Corrections Commons

\section{Recommended Citation}

Kathryn Zeiler \& Erica Puccetti, Crime, Punishment, and Legal Error: A Review of the Experimental Literature, Boston University School of Law, Law and Economics Research Paper (2018).

Available at: https://scholarship.law.bu.edu/faculty_scholarship/418 
Note: This is an incomplete working draft. Please do not cite without authors' permission.

\title{
Crime, Punishment, and Legal Error: A Review of the Experimental Literature
}

\author{
Kathryn Zeiler ${ }^{1}$ and Erica Puccetti ${ }^{2}$ \\ August 2018
}

\section{Introduction}

When individuals violate the law, detection and verification of the violation are rarely, if ever, perfect. Before the state can dole out punishment, it must first identify a suspect and then produce sufficient evidence to persuade a judge and/or jury beyond some threshold level of confidence that the suspect, in fact, violated the law. The court might be uncertain that the state has the right person. If the suspect is undoubtedly the one who caused the harm, the court might be unsure about whether his act constitutes a violation of the law (e.g., whether the suspect was, in fact, speeding). The state, given the level of resources allocated to law enforcement, might not be able to produce a suspect.

Limitations on enforcement resources lead to imperfect detection. Evidence production and proof problems cause both mistaken convictions and mistaken acquittals. ${ }^{3}$ Errors have many sources, including hindsight bias, ${ }^{4}$ lack of complete information about the defendant's possible options and chosen action, untrustworthy eyewitness testimony, the admission of impartial evidence in trials, ${ }^{5}$ and unwillingness or inability to expend resources on detection, ${ }^{6}$ among others. ${ }^{7}$ We focus here not on the sources of errors, but rather on their effects on deterrence and punishment policy. ${ }^{8}$ Our purpose is to briefly summarize the theoretical

\footnotetext{
1 Nancy Barton Scholar and Professor of Law, Boston University School of Law. kzeiler@bu.edu. Thanks to Tim Friehe, Nuno Garoupa, Murat Mungan, and JJ Prescott, for helpful comments and suggestions.

${ }^{2}$ Boston University School of Law, Class of 2019.

${ }^{3}$ Lack of detection of wrongdoing might be viewed as a type of mistaken acquittal. We note, however, that some analyses view these two phenomena as importantly distinct from one another. In addition, the use of "type I" and "type II" errors is common in the literature, although the terms are used inconsistently. For this reason, we prefer "mistaken conviction" and "mistaken acquittal."

${ }^{4}$ See, for example, Fischoff 1975; Baron and Hershey 1988; Casper, Benedict, and Perry 1989.

${ }^{5}$ See, for example, Landsman and Rakos 1994; Kassin and Sommers 1997.

${ }^{6}$ See, for example, Becker 1968.

${ }^{7}$ See Gould and Leo 2010.

${ }^{8}$ We also do not review the substantial literature related to the normative questions around error rates. See, for example, Volokh 1997.
} 
Note: This is an incomplete working draft. Please do not cite without authors' permission.

literature that studies the effects of legal errors on crime and punishment rates, and to critically review studies that report on experiments conducted to test such theories. ${ }^{9}$ The theoretical literature includes analyses of both criminal law and civil law violations, and so we cover both here. ${ }^{10}$

Experimentalists have tested relevant theories in a variety of contexts. We limit our review to theft game experiments, where players handing out punishments are not victims of the crime. Theft game players are assigned to just one role, either judge or potential law violator (citizen, criminal, and so on). Fines are not costly to judges, at least in monetary terms. ${ }^{11}$ This rules out experiments using public goods games that allow players to impose costly punishment on non-contributors.

Researchers who attempt to test theories using field data face formidable obstacles. Much of what is required is unobservable. Data on the number of crimes committed, the amount of resources and effort spent on detection, and rates of wrongful convictions and acquittals are impossible to observe in the field. The lack of randomization of detection efforts, punishment severity, and burdens of proof lead to troublesome selection effects. Despite these difficulties, a great deal of field research has been conducted. ${ }^{12}$ Given the limitations of the field, data generated in the lab can help to increase confidence, or call into question, theories constructed to explain and predict behavior.

While the lab is well suited to solve some of the identification problems that plague researchers working in the field, it is not a perfect tool by any means. It comes with its own substantial limitations. For example, it's impossible to impose severe levels of punishment, such as hefty fines that go well beyond endowments handed out in the lab. Imprisonment of any significant duration is certainly not an option. For this reason, it's impossible to test theories that assume or predict severe penalties such as fines equal to the convict's total wealth. Even testing the effects of varying substantial fines is difficult. At most (at least in the U.S.), we are limited to taking only (or not much beyond) what the subject earned or was given during the experiment and ending the subject's ability to gain additional payouts during the experiment. This and other limitations are discussed, and their implications are explored.

This is not the first review of the experimental literature. Engel (2016) summarizes a wide array of experiments. Our review is much narrower in scope and offers a critical perspective. We attempt to synthesize experimental results to

\footnotetext{
${ }^{9}$ We draw on theoretical literature summaries by Garoupa (1997) and Prescott (2016).

${ }^{10}$ We use language associated with crimes throughout the review. The reader should read the terms broadly - we mean them to encompass civil law violations as well.

${ }^{11}$ Some have studied the effects of allowing law enforcers to profit from delivering punishment. See, for example, Xiao and Tan (2014).

${ }^{12}$ See, for example, Levitt and Miles 2007; Levitt and Miles 2006.
} 
Note: This is an incomplete working draft. Please do not cite without authors' permission.

get a sense of the main take-aways and to generate a roadmap for further exploration in the lab.

Part 2 summarizes theories offered to explain and predict how imperfect detection and guilt-determination errors affect crime and punishment rates. Part 3 summaries, synthesizes and critiques experimental studies designed to test the theories. Part 4 catalogs, in broad terms, where we are and offers ideas for potentially fruitful avenues for continued exploration in the lab.

\section{Theory}

\subsection{Becker's Theory of Optimal Enforcement and Early Responses}

According to standard economics models, one will choose to violate a legal rule if one's expected benefits of doing so outweigh the expected costs. ${ }^{13}$ Perhaps the most salient expected cost is punishment, the likelihood of which depends on three factors: detection, successful prosecution, and punishment enforcement. If the judicial system is able to perfectly determine guilt and detection always leads to prosecution, then one will expect to suffer the cost of punishment if (1) one violates a legal rule, (2) that violation is detected, and (3) punishment is enforced. ${ }^{14}$ Becker (1968, n.55) suggested that enforcement costs could be saved by increasing the severity of punishment beyond the harm resulting from the violation. ${ }^{15}$ In effect, this implies that enforcers can reduce total social costs by reducing enforcement costs to near zero. While reducing enforcement would otherwise greatly increase the likelihood of mistaken acquittal (in the form of imperfect detection), increasing punishment severity maintains the expected cost of crime, which acts to keep would-be criminals in line.

Becker's approach led to a flurry of responses, all of which claimed that Becker's analysis missed crucial factors. Harris (1970), for example, argued that efficient crime policy must account for social costs imposed both by mistaken convictions and mistaken acquittals. Becker suggests increasing the probability of detection to reduce losses from crime or, if doing so is costly, imposing harsher punishment. If, however, social costs arise from unjust punishment and detection mechanisms are not perfect, Harris argues that these social costs must be balanced against the costs of crime and might call for reduced levels of detection and punishment and greater legal safeguards to prevent mistaken conviction. In other words, as long as uncertainty over guilt exists, justifying extreme punishment is

\footnotetext{
${ }^{13}$ See, for example, Becker (1968), which applies standard economics concepts to crime.

${ }^{14}$ We use "guilt" to refer both to violation of criminal or civil laws.

${ }^{15}$ Becker (1968) did not take up the issue of guilt determination errors.
} 
Note: This is an incomplete working draft. Please do not cite without authors' permission.

difficult. ${ }^{16}$ Erlich (1982) points out distributional considerations missing from Becker's (1968) analysis. For example, if detection is unlikely and punishment severe, most will face no punishment and the few unlucky detected criminals will pay a huge cost. Erlich refers to this as ex post inequality. Like Harris, he also argues that any analysis of optimal crime policy must include the costs of mistaken convictions.

The following subsection summaries a number of theoretical models that more formally analyze the implications of mistaken convictions.

\subsection{Early Theories Of Mistaken Convictions}

A number of theorists extended Becker's model to illuminate the implications of mistaken convictions. Stigler (1970) was perhaps the first to point out that mistakenly punishing the innocent might result in higher crime rates. In the extreme, if the innocent will be punished with certainty, then committing crimes that produce benefits of any size is optimal. More generally, the risk of being mistakenly punished decreases the marginal benefits of maintaining one's innocence. Stigler also analyzed the relationship between punishment severity and choice over crimes. He noted that when criminals chose from a continuum of crimes, higher punishments might compel more harmful crimes (e.g., if my hand will be cut off when I'm caught stealing $\$ 5$, I might as well steal $\$ 5,000) .{ }^{17}$ The generality of this result, Stigler notes, depends on actions potential victims might take to prevent crime. Specifically, when criminals assess their options, they consider steps owners of relatively large sums of cash might take to deter theft. Stigler notes that self-protection mechanisms might reduce the likelihood of highdollar crimes.

Rubinfeld and Sappington (1987) consider the use of policy to improve the accuracy of guilt determinations. Their model assumes defendants use trials to signal their innocence or guilt. They find that optimal choices of standards of proof and punishment severity can minimize the probability of mistaken convictions and mistaken acquittals and total litigation costs of defendants. They employ a standard signaling model to show that these two policy levers can be used to increase the court's ability to infer guilt or innocence from defendants' litigation efforts.

Grady (1983) analyzed the effects of perceived error in court guilt determinations on the rate of legal rule violations. He focused not on judicial error

\footnotetext{
${ }^{16}$ Harris also points out the complexities that arise from the fact that different classes of persons might perceive costs of punishment and costs of crime differently.

${ }^{17}$ Malik (1990) points out that we can solve this problem by lowering the probability of detection as punishment severity is increased. Assuming risk neutrality, we can use both levers simultaneously to keep the expected cost of crime constant but lower detection costs. For more on the impact of risk preferences see infra.
} 
Note: This is an incomplete working draft. Please do not cite without authors' permission.

but on potential litigant error in predicting court determinations of violations of duties of care. He assumes that courts do not err in determining breach, but that potential injurers sometimes fail to perfectly predict whether their choice of precautions will trigger a court determination of breach in the event an injury occurs and a negligence suit is pursued. Unlike previous models, his analysis predicts that, assuming such errors, efficient precaution taking will not be encouraged by the standard negligence rule adopted in economic models, which assumes that the defendant breaches his duty of care if his chosen precaution falls below the level of precaution that minimizes the sum of expected harm and precaution cost. Grady $(1983,821)$ proposes a revised rule aimed at encouraging efficient choices over precautions, a rule he claims courts actually apply in practice. $^{18}$

Png (1986) analyzes errors courts make in determining guilt, considering their effects both on behavior given a decision to engage in risky activity and on the decision whether to engage in a risky activity in the first instance. Png assumes a positive probability of both wrongful acquittals and wrongful convictions, that precautions are costly, and that the choice over precautions is binary. Assuming risk neutrality, Png finds that optimal choices over both precautions and activity levels can be encouraged by increasing damages and by offering a subsidy for (or imposing a tax on) activities, depending on the probabilities of wrongful convictions and acquittals. Under this set of assumptions, he finds that both wrongful acquittals and wrongful convictions reduce deterrence and thus compel an increase in punishment severity (in other words, increased damages). ${ }^{19}$ The logic behind wrongful acquittals is straightforward-the lower one's likelihood of detection or conviction given detection, the more severe the punishment must be to push expected costs of rule violation above expected benefits. The connection between wrongful convictions and deterrence is consistent with Stigler's (1970) intuition. As the chance of a wrongful conviction increases, the marginal cost of violating the law decreases. Ignoring social costs of wrongful convictions, Png argues that the possibility of wrongful conviction suggests that Becker's recommended increase in punishment severity to account for low detection rates might not go far enough. To the extent that punishment can be made even more severe, enforcers should increase its severity to account for the possibility of wrongful convictions.

\footnotetext{
${ }^{18}$ The details of the rule, which hinge on a complex relationship between the tort elements of breach and causation, are beyond the scope of our analysis. See Polinsky and Shavell [2000] for a summary of results related to civil liability contexts.

${ }^{19}$ Png assumes that the two types of errors affect deterrence in the same way. Polinsky and Shavell (2000), in their summary of the literature on optimal enforcement in the face of imperfect detection and guilt-determination errors, report this result among others summarized here. Polinsky and Shavell (2007) provide a similar summary.
} 
Note: This is an incomplete working draft. Please do not cite without authors' permission.

Kaplow and Shavell (1994) develop a model to examine optimal enforcer choices over sanctions and methods to improve accuracy of both conviction and acquittal decisions. Their insight is that detection rates and accuracy rates are substitutes in the battle to reduce crime rates; thus, optimal law enforcement will depend on the relative costs of increasing detection and increasing accuracy. The model produces two main results. First, like Becker (1968), they find that increasing costless sanctions will maintain deterrence while allowing detection and judicial accuracy cost savings. While Becker recognizes potential limits on sanctions, Kaplow and Shavell argue that, if imposing sanctions is costless (for example, imposing an easy-to-collect fine), the optimal sanction is the maximal feasible sanction - the entire wealth of the convict. ${ }^{20}$ Second, if sanctions are costly (for example, a prison term), then the enforcer should increase accuracy and reduce enforcement costs relative to a costless sanction environment. Like Png (1986), Kaplow and Shavell ignore social costs of wrongful convictions.

Around the same time, a number of studies considered wrinkles that might alter basic predictions of the early models incorporating mistaken convictions. The following subsection highlights a number of refinements.

\subsection{Enforcement Model Refinements}

\subsubsection{Risk Preferences}

Polinsky and Shavell (1979) analyze the effects of risk aversion on choices over whether to comply with legal standards. They show that any adjustment to punishment to account for a positive probability of wrongful acquittal (in the form of failed detection) needs to account for the risk preferences of potential law violators. For example, if potential violators are risk averse, increases to damages to account for a low probability of detection need not be as high as Becker (1968) suggests based on the assumption of risk neutrality. ${ }^{21}$ In fact, by holding back on damages, Polinsky and Shavell argue that we gain social value by reducing the cost of bearing risk imposed on potential violators. They also find that, if both wrongful convictions and wrongful acquittals are possible, risk aversion leads to ambiguous results on the optimal sanction.

\subsubsection{Jury Preferences for Justice}

\footnotetext{
${ }^{20}$ Becker (1968, n.55) admits that sanctions in excess of the value of the harm are necessary when the probability of detection is less than 1. Becker $(1968,195)$ explicitly rejects, however, tying the penalty to the convict's wealth.

${ }^{21}$ Kaplow and Shavell (1994) find a similar result. They also find that optimal sanctions might rise or fall as mistaken conviction and acquittal rates increase.
} 
Note: This is an incomplete working draft. Please do not cite without authors' permission.

Until the early-90s, economic analyses of criminal law and deterrence focused mostly on choices over enforcement expenditures and severity of sanctions by officials aiming to minimize the sum of enforcement costs and costs imposed by criminals on their victims. Andreoni (1991) explored the effect of severe punishment on the willingness of judges and jurors to convict when guilt is uncertain. Specifically, Andreoni noted that severe penalties might make conviction less likely because jurors are reluctant to impose harsh punishments in the face of uncertainty about guilt, especially in cases where the burden of proof is high (for example, beyond a reasonable doubt). Such reluctance changes the enforcer's calculus. Increasing the severity of punishment given such reluctance to convict might lead to lower convictions rates and, consequently, higher violation rates. This calls into question Bentham's (1914) general claim that regulators and courts should increase penalty severity to balance the effects of low detection rates. ${ }^{22}$

Schrag and Scotchmer (1994) extended the standard model by exploring potentially divergent objective functions of different parties involved in the enforcement apparatus. In particular, they suggest that jurors might care more about justice than they do about deterrence, which could compel them to apply a high evidentiary standard (regardless of the legal standard) when deciding guilt. They assume that justice is maximized when the likelihood of wrongful conviction is minimized; thus, jurors apply high evidentiary standards to reduce the probability of convicting the innocent. They offer an extreme example to make the point. If only one person had an opportunity to commit a perpetrated crime, but the jury is uncertain about who committed it, to maximize deterrence it should convict anyone charged. ${ }^{23}$ This result follows from Png's (1994) insight that mistaken convictions decrease deterrence; but, as Schrag and Scotchmer point out, this is true only for those with an opportunity to commit the crime. The choices of those without an opportunity to commit the crime will not be affected by the possibility of wrongful conviction. If, however, jurors aim not to deter but to minimize wrongful convictions instead, then they will resist convicting, and deterrence will be suboptimal. ${ }^{24}$ They propose allowing into evidence what courts generally

\footnotetext{
${ }^{22}$ Feess and Wohlschlegel $(2009,71)$ formalize this claim and find that "deterrence maximizing punishments are increasing in the quality of information the jury gets."

${ }^{23}$ Schrag and Scotchmer refer to these types of crimes as "exclusive." They also consider non-exclusive crimes (those that many have an opportunity to commit). For these types of crimes, wrongful convictions decrease the deterrent effect to a larger extent than for exclusive crimes. They also consider environments populated by two different types of citizens, some who enjoy high benefits from crime and others who gain less in benefits.

${ }^{24}$ They assume that the jury's objective function, which focuses on justice, is not in line with society's objective function, which focuses on deterrence. They also explore the
} 
Note: This is an incomplete working draft. Please do not cite without authors' permission.

consider prejudicial information about the defendant's character, and they suggest that if those charged are more likely to have criminal records, the information about character will increase the conviction rate and, as a result, increase deterrence. $^{25}$

\subsubsection{Criminal Reactions to Enforcement Policies}

Calfee and Craswell (1984) call attention to the link between the law violator's actions and the likelihood of being found guilty. ${ }^{26}$ They predict, like others, that increases in punishment severity might alleviate the undesirable effects of wrongful acquittals and failed detection on deterrence. In cases where the risk creators' actions are tied to the likelihood of being found guilty, however, the authors predict that risk creators will over-comply when they are uncertain about whether they will be held accountable. Increasing the severity of punishment, they warn, only exacerbates this inefficiency. Calfee and Craswell show that Bentham's (1914) argument that punishment should always be increased to reflect the likelihood of non-detection is valid only when certain conditions hold. ${ }^{27}$ When the potential injurer chooses from a set of continuous actions, such as choosing a driving speed, and the potential injurer's choice affects the likelihood of a guilt determination such that risk creators are encouraged to over-comply, then increasing penalties to compensate for uncertainty in detection might lead to even higher levels of overcompliance. They, like Grady (1983), suggest changing legal rules to directly reduce uncertainty, such as employing bright line rules instead of standards, although they caution that such rule changes might trigger other costs.

implications of juries that are more likely to convict those with criminal records in an effort to punish them for undetected crimes.

${ }^{25}$ For a comprehensive analysis of the role of evidentiary rules in guilt determination errors, see Posner [1999]. Posner assumes that errors in guilt determinations impose a social cost and that costly expenditures to procure evidence reduce the likelihood of such errors. He invokes the intuition from Png (1986) that both wrongful acquittals and wrongful convictions decrease the deterrent effects of the law, and, like Kaplow and Shavell (1994), predicts that greater accuracy in guilt determinations will enhance deterrence.

${ }^{26}$ In addition to legal system errors, they consider other sources of uncertainty including mistaken predictions about where the court will set the legal standard, whether a legal proceeding will be pursued, and the magnitude of the punishment. Shavell (2009) develops this point further. [search for second Calfee and Craswell article that produces a similar result]

${ }^{27}$ The conditions are: (1) when the potential injurer makes an either/or choice rather than a choice from a continuum with an interior optimal point; (2) when the choice is from a continuum and the choice is independent of the probability of detection and litigation; and (3) given a set of choice conditions, under-compliance is more likely than over-compliance (Calfee and Craswell 1984, 996). 
Note: This is an incomplete working draft. Please do not cite without authors' permission.

Malik (1990) considers reactions by criminals to severe penalties and their implications for optimal crime policy. [more here]

\subsubsection{Distinguishing Error Type}

Strandburg (2002)—assumes that errors depend on one another; increase in accuracy has ambiguous effects on deterrence. [more here]

Similar to Schrag and Scotchmer's (1994) basic intuitions related to exclusive crimes (that is, the choices of those without opportunities to commit the considered crime will not be impacted by the probability of wrongful conviction), Lando (2006) draws a distinction between two different sources of wrongful conviction for nonexclusive crimes (in other words, everyone has an opportunity to commit the crime). The first source is a court finding that the defendant violated the law while acting, when in fact his action complied with the law ("mistaken act evaluation"). In this case, the usual result holds if the act is binary. ${ }^{28}$ When the court is mistaken about the wrongfulness of the act, both mistaken conviction and mistaken acquittal reduce deterrence. The second source is a court finding that the defendant committed a criminal act that was actually committed by someone else "mistaken identity"). When the court is mistaken about identity and the probability of mistaken act evaluation is zero, mistaken convictions based on an identity error will not affect choices of those who might be mistaken for the perpetrator. This is because mistaken conviction based on identity is equally likely both when one violates the law and when one decides to comply. Importantly, Lando implicitly assumes that the likelihood that one will be mistakenly acquitted is independent of the likelihood of someone else being mistakenly convicted of one's crime. Lando, thus, highlights the importance of considering the error type when analyzing the effects of errors on deterrence.

Garoupa and Rizzolli (2011) call into question Lando's conclusion. They point out that whenever a misidentified defendant is mistakenly convicted, the actual perpetrator is mistakenly acquitted. Thus, the probability of mistaken acquittal is a function of the likelihood that someone else will be found guilty of one's crime. In the extreme, if the jury always convicts the wrong person, then everyone who benefits from committing a crime will commit it. Garoupa and Rizzolli therefore

\footnotetext{
${ }^{28}$ The act is binary if the choice set is \{commit the act, do not commit the act\}. Lando reminds us of Calfee and Craswell's (1986) qualification related to continuous choice sets (for example, how fast to drive). In these cases, if the choice impacts the likelihood of guilt, then actors are encouraged to be overly cautious. Mistaken guilt determinations exacerbate this effect.
} 
Note: This is an incomplete working draft. Please do not cite without authors' permission.

conclude that convictions based on mistaken identities will, in fact, reduce deterrence. $^{29}$

\section{Experiments (and Theory Development)}

\subsection{Criminal Preferences}

Some of the first experiments designed to explore reactions to changes in the likelihood of detection brought to light factors beyond expected punishment that might keep potential law violators in line.

In one of the first lab experiments in the field, Alm, McClelland, and Schultze (1992) considered tax evasion rates given low levels of detection and found evidence of overestimation of low detection rates and a willingness to comply due to preferences for the provision of public goods. Subjects were endowed with various incomes and told to decide how much income to report. They were told that they must pay a tax on all reported income and that, with some positive probability that varied within subject across multiple rounds, a penalty equal to fifteen times the unpaid tax would be imposed if they did not report all income. To test whether subjects might be influenced by the public-goods benefits that arise from taxes, all collected taxes and penalties were put into a group fund, increased by some multiple, and distributed equally among all subjects at the end of each round. To avoid introducing negative connotations, the loaded words "evasion" and "tax compliance" were not used during the main experiment. ${ }^{30}$

It is important to note at the outset that the design features deviate from the assumptions of the general deterrence models. First, evidence suggests that subjects view money given to them by the experimenter as different from their own money. This "house money effect" can reduce the disutility subjects experience when they lose amounts during the experiment. ${ }^{31}$ Second, penalties are limited by the amounts subjects obtain during the experiment. General experimental protocol frowns upon (and in some cases forbids) the taking of money not endowed during the

\footnotetext{
${ }^{29}$ Garoupa and Rizzolli employ an equilibrium model of the supply of and demand for errors to derive their conclusion, though it seems that simply assuming the likelihood of a wrongful acquittal is a function of the likelihood of a wrongful conviction of another for one's crimes is sufficient to obtain the result.

${ }^{30}$ Some treatments were run with the loaded terminology to test for its effects, however, and no differences in choices were observed. This suggests that results reported in previous experiments that used the loaded terms might not have been tainted in any way by the suggestive language.

${ }^{31}$ Cite to basic house money effect literature.
} 
Note: This is an incomplete working draft. Please do not cite without authors' permission.

experiment. ${ }^{32}$ Experiments in such environments are not effective tests of theories that assume criminal penalties go beyond gains from the crime that triggered the penalty.

The results suggest that at least some individuals place excessive weight on low probability events as assumed by Kahneman and Tversky (1979), and that some pay taxes because they value public goods funded by tax revenues. When the subjects were told that the probability of detection was zero, average group compliance was $20 \%$, suggesting forces other than probability overweighting were at play. The authors do not tell us whether subject choices and payouts were anonymous. Thus, we cannot rule out the possibility that subject choices were at least partly driven by the desire to avoid signaling to the experimenters or other subjects a willingness to break the law. That said, the results suggest that choices might be driven at least in part by systematic overestimation of low probabilities of detection and preferences over public goods produced through compliance. While the experiment environment is not in line with assumptions of theories of crime and punishment, which assume that criminals pay penalties out of total wealth and not just the profits from their crimes, the results provide some insight into factors that might influence criminals' choices.

Block and Gerety (1995) report results suggesting that, in the face of uncertain likelihood and severity of punishment, convicts react differently from a deterrence standpoint from the general population. Becker (1968) and others have noted that convicts tend to be risk seeking. In contrast, ample experimental evidence shows that the general population is risk averse. This implies that convicts, when deciding whether to commit a crime, might be more sensitive to changes in the certainty of punishment than to its severity, while the general population might be relatively more sensitive to changes in punishment severity.

Block and Gerety (1995) collected data from two samples, one drawn from a prisoner population and another from a college student population. All subjects participated as sellers in binding auctions over multiple rounds. Subjects were assigned costs of production - the same across all subjects—and asked to report the lowest price at which they would be willing to sell a "make-believe commodity." The seller reporting the lowest price sold a number of units indicated by a predetermined demand function and received compensation equal to the number of units demanded multiplied by the per-unit profit (price minus the per-unit production cost). All other subjects received nothing. In some rounds, subjects were allowed to communicate, which provided an opportunity to collude. In others, subjects could communicate with each other but were told they would

${ }^{32}$ Generally, human subjects committees in the U.S. forbid net experimental earnings to be negative. [add cite] Journals outside the U.S., however, do not always require authors to obtain human subjects committee approval, and negative payoffs are, therefore, possible (see, for example, Fehr and Fischbacher, 2004, 67). 
Note: This is an incomplete working draft. Please do not cite without authors' permission.

suffer a monetary penalty of some (varying) size with some (varying) probability if the experimenter detected collusion (that is, if the reported prices exceeded the cost of production). ${ }^{33}$ The findings supported the assumptions related to risk preference differentials between prisoners and students. In the rounds forbidding communication, prices converged to the production cost. In the unpunished collusion rounds, prices generally converged to the monopoly price, implying that subjects successfully colluded. In rounds imposing varying punishment with varying probability, students generally displayed aversion to risk while the prisoners engaged in risk-seeking behavior, in line with predicted differences. Thus, the results suggest the existence of heterogeneous risk preferences when wrongful acquittal is possible. ${ }^{34}$

Abbink, Irlenbusch, and Renner (2002) designed an experiment to study choices in environments in which bribes are possible. They focused on three drivers of behavior: beliefs over reciprocity (in other words, if the enforcer is bribed, he will reciprocate), known costs imposed on third parties (citizens incur corruption costs), and fear of detection and punishment. ${ }^{35}$ To test other-regarding preferences, bribers in some treatments were told that all other subjects participating in the experiment would suffer a small loss if a bribe were accepted. To test fear of punishment, bribers in some treatments were told that they faced a 0.003 probability of detection, which would result in a loss of all money made during the experiment and the end of opportunities to earn more during the experiment. Subjects did not know when others were detected and essentially ejected from future rounds, and payouts were made anonymously at the end of the experiment. The results reject the hypothesis that other-regarding preferences will reduce bribes. Costs imposed on others did not affect the crime rate. On the punishment front, the possible loss of all winnings reduced (over all rounds) the number of bribes despite the overall low probability of sudden death ${ }^{36}$ and subjects' underestimation of the probability of detection elicited using surveys administered after all treatments. Based on subject choices and survey responses,

\footnotetext{
${ }^{33}$ Relatively hefty punishments were possible because these rounds followed rounds in which subjects were given opportunities to engage in unpunished collusion and accumulate winnings. Punishment, however, never exceeded the amount of money gained from "criminal" activities during the experiment. Thus, the conditions of the experiment diverge from the assumptions of the tested theories.

${ }^{34}$ The experiment does not test the deterrent effects of wrongful conviction.

${ }^{35}$ Bribers were randomly matched with "public officials," and each matched pair engaged in thirty consecutive rounds with payoffs accumulating over rounds.

${ }^{36}$ The probability of sudden death over all rounds was 0.086 .
} 
Note: This is an incomplete working draft. Please do not cite without authors' permission.

the authors concluded that deterrence was driven by severity of the punishment as opposed to the likelihood of detection. ${ }^{37}$

\subsection{Wrongful Conviction v. Wrongful Acquittal}

Basic theories (for example, Png 1986) predict that risk neutral citizens react to wrongful convictions rates and wrongful acquittal rates in the same way. Rizzolli and Stanca (2012) conducted an experiment (1) to test Png's claim, and (2) to study what might explain disparities in reactions if they exist. They offered three potential explanations for disparities: risk aversion, loss aversion, and mistaken conviction aversion. ${ }^{38}$ Rizzolli and Stanca designed two experimental studies-one withinsubjects and another between-subjects ${ }^{39}$-in which subjects, under various probabilities of wrongful conviction and acquittal, chose whether (anonymously) to take money from another randomly matched subject. ${ }^{40}$ Both subjects in the pair were given endowments, which were not common knowledge. ${ }^{41}$ One subject decided whether to take a fixed amount, g, from the other. If convicted, the subject paid a fixed sanction, $\mathrm{f}$, but kept $\mathrm{g} .{ }^{42}$

The results from the within-subject experiment provide mixed support for Png's theory. In Treatment 1 , subjects $(n=48)$ faced no chance of a wrongful conviction or acquittal. All theories predict indifference between taking and not taking. Just over $29 \%$ of subjects took g. In Treatment 2 , the probability of a wrongful acquittal increased to 0.5 . In Treatment 3, the probability of a wrongful conviction increased to 0.5 . In Treatment 4 , the probability of a wrongful acquittal and a wrongful

37 The authors did not report correlations between individual underestimation of probabilities and choices over whether to bribe. This would have increased our confidence in the authors' conclusion.

${ }^{38}$ Aversion to wrongful convictions implies that individuals tend to follow the law because it is the right thing to do, and not merely because it is optimal for them to abide by the rules. Thus, wrongful convictions impose a greater cost relative to wrongful acquittals because they trigger a "loss of guidance" and "motivational crowding out."

${ }^{39}$ The between-subjects experiment rules out order effects. Each subject participated in just one treatment.

${ }^{40}$ No feedback was provided to subjects between rounds in the within-subject experiment.

${ }^{41}$ This helps to rule out inequity aversion as an explanation for observed choices. The authors ran additional tests to determine whether subjects might have assumed all endowments were the same and acted in a way to avoid inequity in payouts. They find no evidence of this.

${ }^{42}$ Subjects were undergraduate students. All subjects read instructions for both roles and had to pass a test of understanding to continue. Perfect stranger matching was used from round to round so that no subject was matched with any other subject more than once. Each player played the role of the thief in every round and payouts were determined by randomly choosing which player was the actual thief. 
Note: This is an incomplete working draft. Please do not cite without authors' permission.

conviction were 0.25 . In all treatments, in line with every theory, the rate of taking increased substantially relative to treatment 1 . Tests of Png's predictions failed to offer support. Theft rates were higher when one error rate increased relative to both (Treatment $2 \mathrm{v}$. Treatment 4 and Treatment $3 \mathrm{v}$. Treatment 4). In addition, the theft rate was higher (at the $10 \%$ level) when the wrongful conviction rate increased alone relative to an increase solely in the wrongful acquittal rate (Treatment $2 \mathrm{v}$. Treatment 3). Thus, contrary to Png's prediction, individuals tend to react differently to different types and combinations of errors.

\section{Figure 1: Within-Subject Crime Rates from Rizzolli and Stanca (2012)}

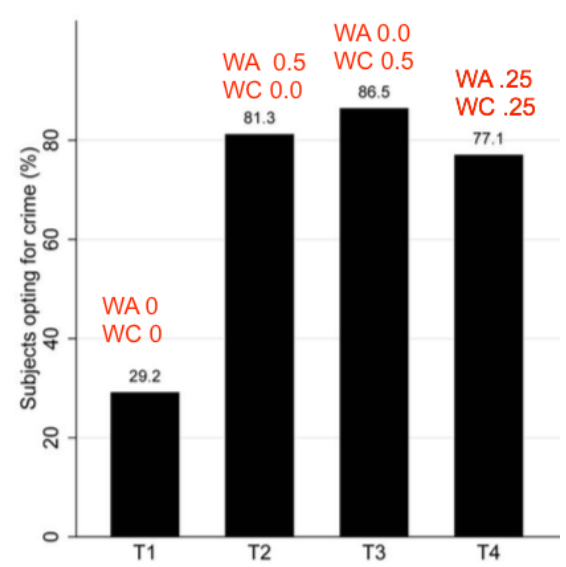

Rizzolli and Stanca designed Treatments 5 and 6 to separate the three possible explanations for varying effects of different error types: risk aversion, loss aversion, and wrongful conviction aversion. Treatment 5 was identical to Treatment 2, except that the thief received no endowment. Treatment 6 was the same as Treatment 3, except the thief received an endowment twice as large. Thus, Treatments 2 and 6 and Treatments 3 and 5 were identical with respect to the expected gains from theft. In the between-subjects experiment (which controls for order effects), the crime rate is higher when wrongful conviction alone is possible relative to only wrongful acquittal, consistent with the within-subjects result. When the initial endowment is changed to control for expected gains from theft, however, the difference disappears. This supports risk aversion as an explanation for the difference in crime rates between Treatments 2 and $3 .{ }^{43}$ Given evidence suggesting

\footnotetext{
${ }^{43}$ The authors argue that these results also rule out wrongful conviction aversion and loss aversion as possible explanations for the different outcomes in Treatments 2 and 3. Presumably, if individuals were averse to wrongful convictions, we should observe differences between Treatments 2 and 6 and between Treatments 3 and 5 because, even though the expected marginal gain from taking is the same, individuals would resist taking when the probability of a wrongful conviction is higher to avoid the disutility that arises
} 
Note: This is an incomplete working draft. Please do not cite without authors' permission.

convicts are risk loving relative to the general population (see, for example, Block and Gerety 1995), however, evidence in support of theories that assume risk aversion are of limited use for policy applications.

Figure 2: Between-Subject Crime Rates from Rizzolli and Stanca (2012)

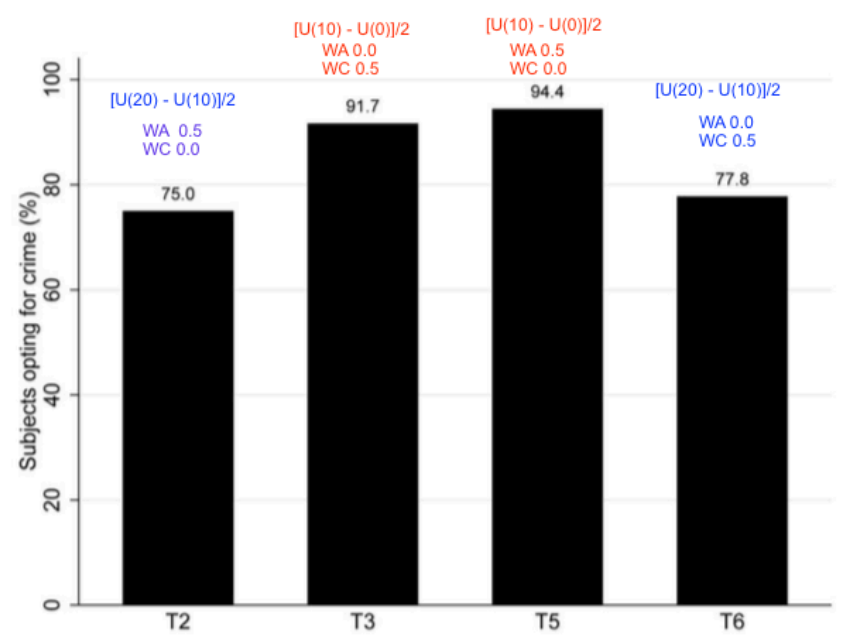

Expected utility expressions indicate marginal gain from stealing given endowment. T2 and T6 (and T3 and T5) are identical except for probabilities of wrongful conviction and acquittal.

\subsection{Enforcer Choices}

Several experiments test predictions related to enforcer choices and the influence of those choices on crime rates.

Rauhut (2009) was one of the first to predict behavior of citizens and law enforcers using a game theoretic model assuming risk neutrality. The model assumes the enforcer pays some fixed cost of detection and earns a positive reward upon detection, and the citizen receives a payoff upon accomplishing an

from the aversion. Similarly, Rizzolli and Stanca argue that if individuals were loss averse, we would observe lower crime rates in Treatment 5 relative to Treatment 3 and Treatment 2 relative to Treatment 6 . This is not the case, however. Predictions will depend on whether taking resets one's reference point. If it does not, then one will always take in Treatments 3 and 5 (taking avoids the chance of a loss from a wrongful conviction in T3, and taking provides an opportunity to keep a gain in T5). If it does, then one will never take in Treatments 3 and 5 (not taking avoids a sure loss in T3 and a chance of a loss in T5). Although the predictions are flawed, the data fail to support loss aversion. 
Note: This is an incomplete working draft. Please do not cite without authors' permission.

undetected taking ${ }^{44}$ and suffers punishment if detected. The probabilities of crime and detection arise as Nash equilibrium mixed strategies-the enforcer sets the detection rate to keep the citizen indifferent between stealing and not stealing, and the citizen sets the taking rate to keep enforcers indifferent between inspecting and not inspecting. The model predicts that (1) as punishment severity increases, enforcers are less likely to expend resources to detect, and (2) severity of punishment has no effect on crime rates.

Rauhut conducted an experiment to test these predictions. A total of 196 subjects participated in one of ten sessions ${ }^{45}$ First, all subjects earned money by taking a general knowledge quiz. ${ }^{46} \mathrm{Next}$, all subjects read instructions for roles of "players" and "inspectors" and were tested for understanding. Each subject was randomly assigned to the role of player or inspector. After participating in two practice rounds, each subject engaged in thirty binding rounds. In each round, each player was anonymously matched with another different player, and both players could decide to take money from the other. Each player was also matched with an inspector (a different inspector each round), and each inspector decided whether to inspect without knowledge of whether the player took from the other player. In one experiment, punishment was light in periods 1-15 and heavy in periods 16-30. In a second experiment, punishment was heavy in the first half and light in the second. After each round, each player learns whether the other player took from her, whether the inspector inspected and, if she took, whether she was punished. Each inspector learned whether the player attempted to take. Payoffs were tallied and accumulated from round to round.

The results generally fail to support the models' predictions. Given the parameters chosen, the expected inspection rate was $80 \%$ in the low punishment rounds and $20 \%$ in the high punishment rounds. The model predicts that, as punishment severity changes, the inspector will adjust the inspection rate to keep the player indifferent between taking and not taking. The expected crime rate, therefore, was $50 \%$ in all rounds (again, partly a function of the parameters chosen). Static regression results suggest that increasing punishment severity reduces both inspection (in line with the static prediction) and theft (against the prediction) ${ }^{47}$ Rauhut also derived predictions using a dynamic learning model. The model assumes that subjects begin with initial expectations and update their priors as they gain experience during the experiment. Figure 3 reports average behavior

\footnotetext{
${ }^{44}$ Transfers due to taking are inefficient in the sense that the payoff to the criminal is some fraction of the value to the original owner.

${ }^{45} 72 \%$ of subjects were female due to their overrepresentation in the subject pool drawn from students enrolled in the University of Leipzig.

${ }^{46}$ This design feature is meant to mitigate house money effects.

${ }^{47}$ Rauhut derived estimates using a linear random intercept model, clustering standard errors on session and subject. Both effects are significant at the $0.1 \%$ level.
} 
Note: This is an incomplete working draft. Please do not cite without authors' permission.

(open and closed connected circles) across rounds in Experiment 1 (low punishment to high punishment) and Experiment 2 (high punishment to low punishment). The thick grey lines are the static Nash Equilibrium predictions. The dotted and solid trends represent predictions from two different learning models. ${ }^{48}$ Citizens seem to react to changes in punishment severity, adjusting theft rates downward when severity increases and upward when they decrease. The same is true for inspection rates only when citizens face low punishment severity in the first rounds and high severity punishment in later rounds. Inspection rates react less sharply when more severe punishment is meted out in the first rounds, even as theft rates initially increase.

To summarize, the results support static predictions that increased severity of punishment lowers inspection rates. Static predictions of stable crime rates are not supported, however. Dynamic models predict that subjects will react much more strongly to punishment incentives than they actually do. Adaptation is slower than predicted. It is possible that over a higher number of rounds, choices would confirm the dynamic predictions.

\section{Figure 3: Results from Rauhut (2009)}
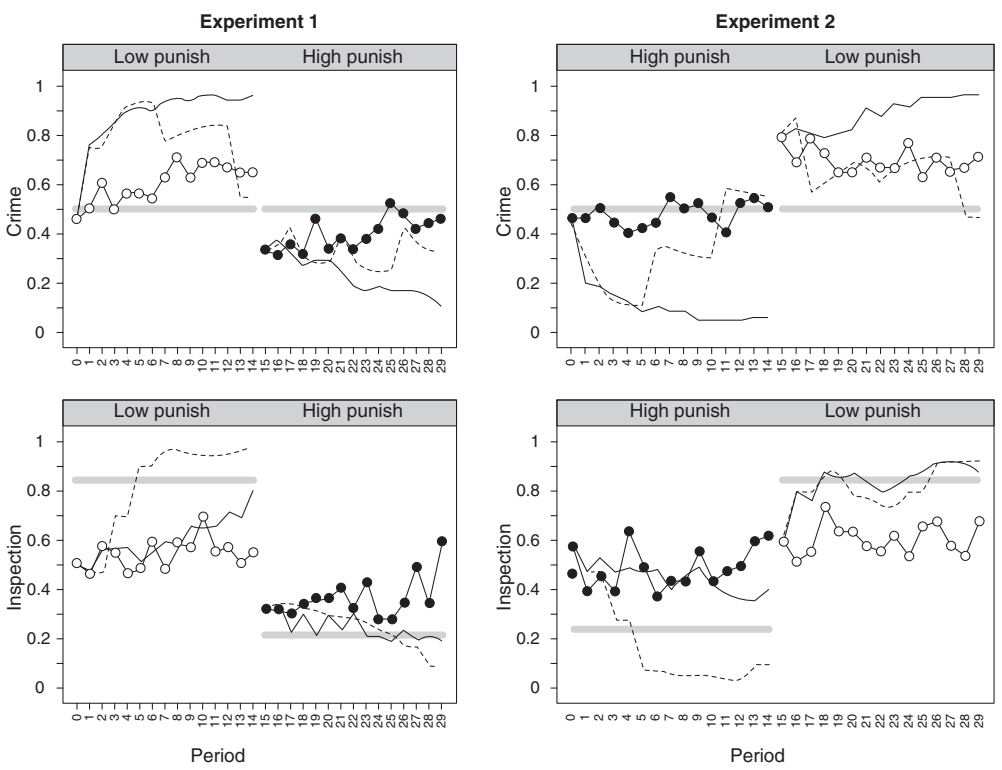

${ }^{48}$ The solid curves are predictions from the unilateral learning model, which uses actual experiment data and assumes that subjects update beliefs using actual outcomes. The dotted curves represent predictions from a bilateral learning model, which uses actual data only from the first round (Round 0 ) and assumes perfect updating given simulated crime and inspection decisions. The bilateral learning model allows comparisons of subjects with perfect updaters who start out with the subjects' priors. 
Note: This is an incomplete working draft. Please do not cite without authors' permission.

\section{Discussion and Conclusion}

[to come] 
Note: This is an incomplete working draft. Please do not cite without authors' permission.

\section{References}

Abbink, Klaus, Bernd Irlenbusch, and Elke Renner. 2002. "An Experimental Bribery Game." Journal of Law, Economics, and Organization 18:428-454.

Aim, James, Gary H. McClelland, and William D. Schulze. 1992. "Why Do People Pay Taxes?" Journal of Public Economics 48:21-38.

Ambrus, Attila, and Ben Greiner. 2012. "Imperfect Public Monitoring with Costly Punishment: An Experimental Study." American Economic Review 102:33173332.

Andreoni, James. 1991. "Reasonable Doubt and the Optimal Magnitude of Fines: Should the Penalty Fit the Crime?" RAND Journal of Economics 22:385-395.

Becker, Gary S. 1968. "Crime and Punishment: An Economic Approach." Journal of Political Economy 76:169-217.

Jeremy Bentham. 1914. Theory of Legislation. Translated from the French of E. Dumont by C.M. Atkinson. Oxford: Clarendon Press.

Block, Michael K., and Vernon E. Gerety. 1995. "Some Experimental Evidence on Differences Between Student and Prisoner Reactions to Monetary Penalties and Risk." Journal of Legal Studies 24:123-138.

Calfee, John E., and Richard Craswell. 1984. "Some Effects of Uncertainty on Compliance with Legal Standards." Virginia Law Review 70:965-1003.

DeAngelo, Gregory, and Gary Charness. 2012. "Deterrence, Expected Cost, Uncertainty and Voting: Experimental Evidence." Journal of Risk and Uncertainty 44:73-100.

Ehrlich, Isaac. 1982. "The Optimum Enforcement of Laws and the Concept of Justice: A Positive Analysis." International Review of Law and Economics 2:3-27.

Christoph Engel, April 2016, Experimental Criminal Law: A Survey of Contributions from Law, Economics and Criminology, working paper no. 2016/07 Max Planck Institute for Research on Collective Goods, Bonn, Germany 
Note: This is an incomplete working draft. Please do not cite without authors' permission.

Feess, Eberhard, and Ansgar Wohlschlegel. 2009. "Why Higher Punishment May Reduce Deterrence." Economic Letters 104:69-71.

Fon, Vincy and Hans B. Schaefer, State Liability for Wrongful Conviction: Incentive Effects on Crime Levels, 163 Journal of Institutional and Theoretical Economics 269 (2007)

Garoupa, Nuno, A Theory of Optimal Law Enforcement, 11(3) Journal of Economic Surveys 267-295.

Garoupa, Nuno and Matteo Rizzolli, Wrongful Conviction Do Lower Deterrence, 168 Journal of Institutional and Theoretical Economics 224 (2012)

Gould, Jon B. and Richard A. Leo, "One Hundred Years Later: Wrongful Convictions After a Century of Research." The Journal of Criminal Law \& Criminology 100(3):825-868 (2010).

Grady, Mark F., A New Positive Economic Theory of Negligence, 92 Yale Law Journal 799 (1983)

Grechenig, Kristoffel, Andreas Nicklisch, and Christian Thoni, Punishment Despite Reasonable Doubt - A Public Goods Experiment with Sanctions Under Uncertainty, 7 Journal of Empirical Legal Studies 847 (2010)

Harbaugh, William T., Naci Mocan, and Michael S. Visser, Theft and Deterrence, 34 Journal of Labor Research 389 (2013)

Harris, John R., On the Economics of Law and Order, 78 Journal of Political Economy 165 (1970)

Kaplow, Louis and Steven Shavell, Accuracy in the Determination of Liability, 37 The Journal of Law \& Economics 1 (1994)

Lando, Henrik, Does Wrongful Conviction Lower Deterrence, 35 J. Legal Stud. 327 (2006)

Lando, Henrik and Murat C. Mungan, The Effect of Type-1 Error on Deterrence, International Review of Law and Economics 1 (2017)

Steven Levitt and Thomas Miles, 2007, Empirical Study of Criminal Punishment in the Handbook of Law and Economics, Vol. 1, edited by A. Mitchell Polinsky and Steven Shavell. 
Note: This is an incomplete working draft. Please do not cite without authors' permission.

Steven D. Levitt and Thomas J. Miles, 2006, Economic Contributions to the Understanding of Crime, Ann. Rev. L \& Soc. 2:147

Malik, Arun, Avoidance, Screening and Optimum Enforcement, 21 RAND Journal of Economics 341 (1990)

Ouss, Aurélie and Alexander Peysakhovich, When Punishment Doesn't Pay: Cold Glow and Decisions to Punish, 58 Journal of Law and Economics 625 (2015)

Png, I. P. L., Optimal Subsidies and Damages in the Presence of Judicial Error, 6 International Review of Law and Economics 101 (1986)

Polinsky, A. Mitchell and Steven Shavell, The Economic Theory of Public Enforcement of Law, 38 Journal of Economic Literature 45 (2000)

Polinsky, A. Mitchell and Steven Shavell, The Optimal Tradeoff between the Probability and Magnitude of Fines, 69 The American Economic Review 880 (1979)

Polinsky, A. Mitchell and Steven Shavell, The Optimal Use of Fines and Imprisonment, 24 Journal of Public Economics 89 (1984)

Polinsky, A. Mitchell and Steven Shavell, The Theory of Public Enforcement of Law, 1 Handbook of Law and Economics 403 (2007)

Prescott, J.J., Criminal Sanctions and Deterrence, Encyclopedia of Law and Economics, ed. A. Marciano and G. B. Ramello (2016).

Rauhut, Heiko, Higher Punishment, Less Control? Experimental Evidence on the Inspection Game, 21 Rationality and Society 359 (2009)

Rizzoli, Matteo and Luca Stanca, Judicial Errors and Crime Deterrence: Theory and Experimental Evidence, 55 Journal of Law and Economics 311 (2012)

Rubinfeld, Daniel and David Sappington, Efficient Awards and Standards of Proof In Judicial Proceedings, 18 RAND Journal of Economics 308 (1987)

Schildberg-Horisch, Hannah and Christina Strassmair. An Experimental Test of the Deterrence Hypothesis, 28 Journal of Law, Economics, and Organization 447 (2012) 
Note: This is an incomplete working draft. Please do not cite without authors' permission.

Schrag, Joel and Suzanne Scotchmer, Crime and Prejudice: The Use of Character Evidence in Criminal Trials, 10 Journal of Law, Economics, \& Organization 319 (1994)

Shavell, Steven. 2009. Economic Analysis of Accident Law, Harvard University Press.

Shavell, Steven, Specific versus General Enforcement of Law, 99 Journal of Political Economy 1088 (1991)

Strandburg, Katherine J., Deterrence and the Conviction of Innocents, 35 Connecticut Law Review 1321 (2003)

Stigler, George J. 1970. The Optimum Enforcement of Laws. 78(3) Journal of Political Economy 526-536.

Volokh, Alexander. n Guilty Men, 146 University of Pennsylvania Law Review 173-211 (1997).

Xiao, Erte and Fangfang Tan, Justification and Legitimate Punishment, 170(1) Journal of Institutional and Theoretical Economics 168-188. 2014. 